\title{
Imaging with a laser photography camera during limited visibility
}

\author{
M. Piszczek*, M. Zarzycki, K. Rutyna, M. Kowalski, M. Karol, M. Szustakowski \\ Institute of Optoelectronics, Military University of Technology, S. Kaliskiego 2, 00-908 Warszawa
}

Received September 19, 2013; accepted March 27, 2014; published March 31, 2014

\begin{abstract}
Present systems for vision monitoring very often employ many different imaging devices working in various spectral ranges, e.g. visible (VIS), near infrared (NIR), infrared (IR). Every single spectral range delivers slightly different relevant information for the process of threats detection, recognition and identification. However, technology progress still does not satisfy every need. Finding new vision solutions, capable of imaging in very difficult conditions (adverse weather conditions, partial occultation of the observed scene) is still one of the most urgent and demanding task for researchers. One of the possible solutions is to use a camera employing a time-spatial framing method. This method is able to minimize the impact of adverse factors on the image acquisition process. A laser photography device (LPD) is a camera developed in the Institute of Optoelectronics, Military University of Technology working according to the time-spatial framing method. The paper presents the theoretical basics and initial results of the laser photography device tests.
\end{abstract}

An important issue for public safety is to ensure effective monitoring of the protected area. Modern vision systems are characterized by very high potential observation therefore play an important role in modern information systems. Technological developments have led to a number of methods of image acquisition and have involved various ranges of the spectrum from the ultraviolet through the visible range of the far-infrared, and even the $\mathrm{THz}$ range. Each band carries slightly different relevant information and involves certain technological limitations. One of the essential needs of today's video surveillance systems is the ability to develop an observation system which will help in getting good quality images regardless of changing lighting conditions (day, night), and the presence of scattering centers in the atmosphere (fog, rain, snow) occurring between the object and the observer scheme.

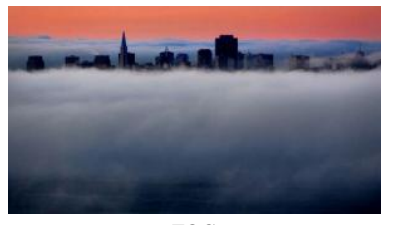

FOG

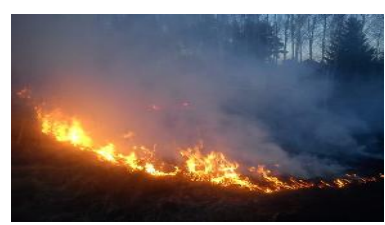

SMOKE

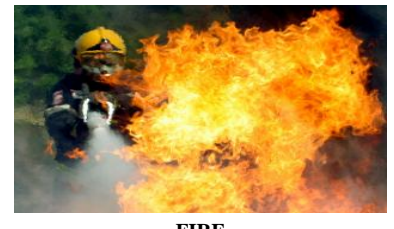

FIRE

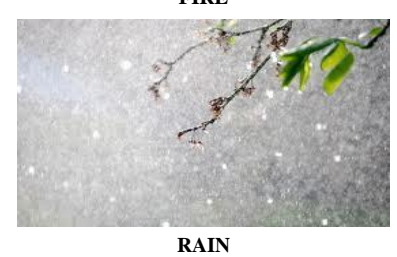

RAIN
Fig. 1. Disorder which prevent vision.
Those presented in Fig. 1 and other difficulties act negatively on the effectiveness of hazard identification, which reduces the application validity of machine vision in the security industry [6].

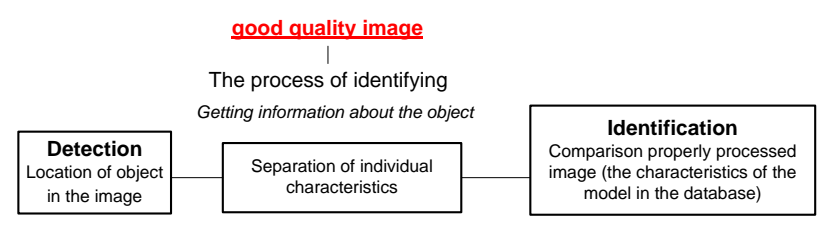

Fig. 2. Process of identifying

The operation developed by the IOE WAT photograph laser device is based on the so-called framing method of space-time, which is one of the most advanced solutions in the field of imaging techniques, combining: possibility distribution of classic vision, decreased sensitivity to prevailing lighting conditions and weather provided by thermal imaging systems as well as the possibility of spatial interpretation of the observed scene, which radar solutions offer.

Currently used technologies allow to minimize the impact of different types of limitations visibility through the use of appropriate hardware and image correction, using for this purpose the processing of complex algorithms.

The most common observation cameras and also commonly used solutions such as video monitoring devices are equipped with sensors to detect radiation from the visible spectrum.

However, they are characterized by a number of limitations. In order to increase the efficiency of detection and identification of objects, a large number of image processing techniques include:

- HLS (Highlight Compensation), which allows the adjustment of strong light (the most classic example being the strong light from the headlights of a car, which makes it impossible to read the numbers, vehicle registration or identification of a person operating a motor vehicle)

- DNR (Dynamic Noise Reduction) - also called the "SSNR" - the technology of dynamic removal of image noise ( being especially useful in low light conditions)

- BACKLIGHT - Back Light Compensation (strong light behind the subject).

- SHARPNESS - auto unsharp image. 


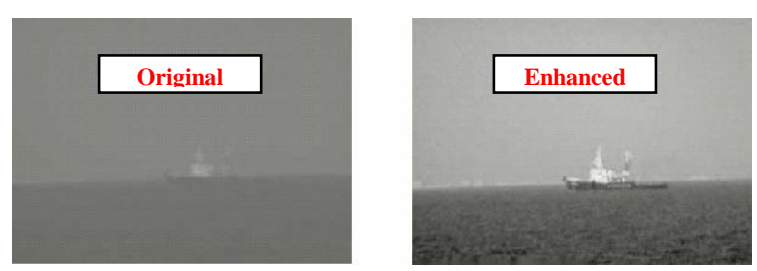

Fig. 3. Software improve image quality.

Besides algorithmic methods, hardware is also used to improve the quality of images. First of all, it involves the use of other spectral bands.

Becoming more popular with the creation of a relatively low cost uncooled 2D matrix is third-generation infrared imaging. The infrared range is divided into five sub [1]:

- range of near-infrared (NIR) $0.78-1 \mu \mathrm{m}$, such as nightvision devices and ICCD cameras

- scope of shortwave (SWIR) $1-3 \mu \mathrm{m}$, such as cameras to visualize the battlefield, the distribution of high temperatures $\left(>200^{\circ} \mathrm{C}\right)$ on the surface of the material [2],

- medium-range (MWIR) 3-6 $\mu \mathrm{m}$, such as thermal imaging cameras

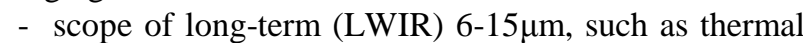
imaging cameras

- extent ultra long-term (VLWIR) $15-1000 \mu \mathrm{m}$.

Observed examples of the same scene in various spectral bands are shown in Fig. 4.

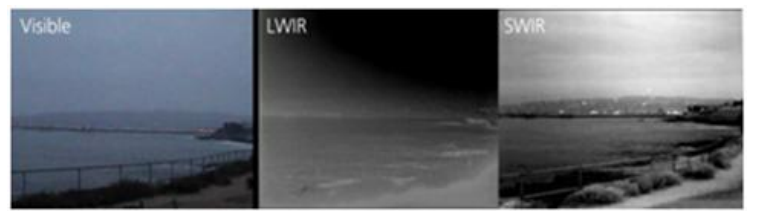

Fig. 4. Various hardware solutions to improve the captured.

In traditional photography, using natural (sometimes artificial) lighting IA scene, the level of illumination, receiver sensitivity and detection time determine the quality of images. In the method of space-time framing natural light is something "parasitic" and should be minimized, which is effected by spectral filtering. A key role is played by the $I_{B}$ and the radiation source is a transmitter/illuminator [3-4]. This part of radiation which, after passing a defined way of measuring $L+\mathrm{d} L$, reaches the receiver (at the time of shutter speed) is involved in the creation of an image [5].

$$
I_{L}=\int_{L}^{L+d L} \int_{\Delta \lambda} I_{B}^{\prime} d L d \lambda
$$

Thus, in the registered frame we can see only the objects that occur at a distance $\mathrm{d} L$. In addition, the result is a minimized masked object (such as fog) occurring between the camera and the observed object. This is due to the properties of Laser Photography, which has a unique opportunity to improve image quality, decoupling it, to a large extent, from the prevailing lighting and weather conditions (Fig. 5)

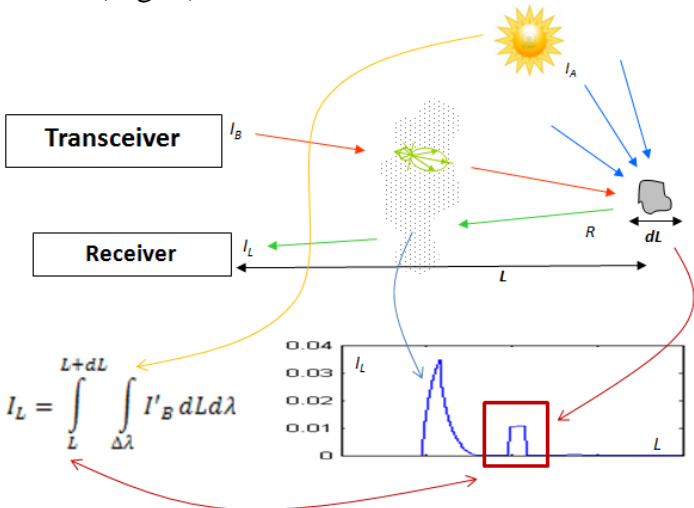

Fig. 5. Modus operandi Laser Photography Technique.

Studies carried out in order to verify the effectiveness of the imagining method using a spatio-temporal crop concerned the introduction of a masking factor in the optical path between the UFL and the subject. For this purpose, a reconfigurable test stand involves acquisition confounders Fig. 6).

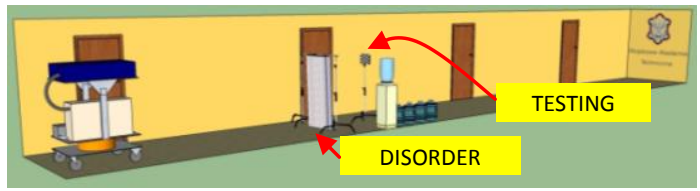

Fig. 6. The test area.

The test to verify the broad outline of the method has been made for the stage arranged as in Fig. 6. Along the axis of observation, just a meter from each other, are placed a masking fabric and a test chart. The experiment consisted of just a step change in the follow-up $(15 \mathrm{~cm})$ at a constant depth of $5 \mathrm{~m}$ observation (Fig. 7).

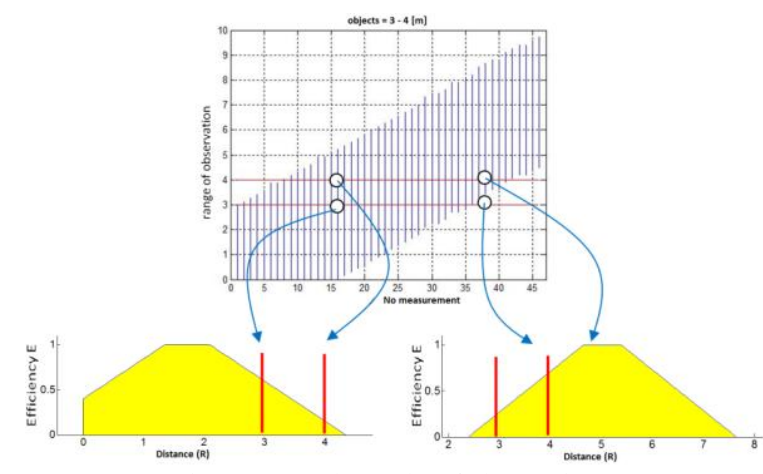

Fig. 7. Example results of observations.

In the tests there was used a camera Photography Laser cooperating with $850 \mathrm{~nm}$ semiconductor illumination and $15 \mathrm{~ns}$ pulse duration.

Tests have shown that with the movement of the observation distance, we see, for closer observation distances, a more exposed fabric and for greater distances - a more exposed test chart (Fig. 8). 
These results clearly confirm the functionality of the method for the selection of spatial imaging and thus minimize the impact of the elements beyond the registered frame spatial image quality.

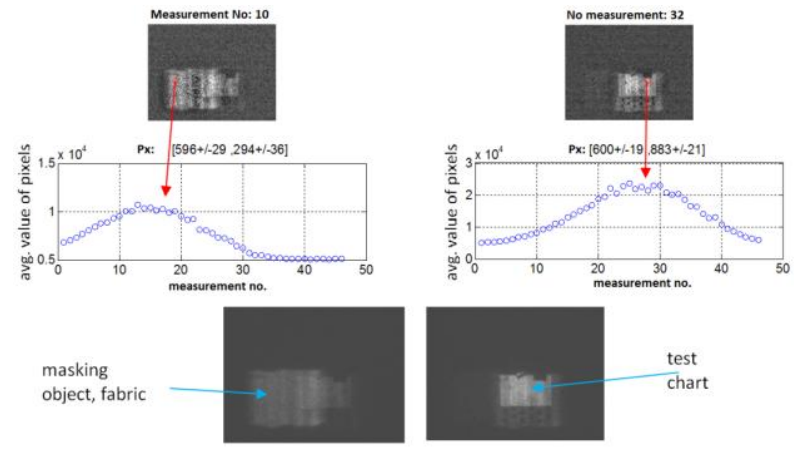

Fig. 8. Example results of observations per measurement no.

A number of other tests were performed in various scales and for the most common possible "obstacles" in the imaging space. The research involved the use of natural (e.g., fire fog, smoke) and material (e.g. textiles) shrouds.

The general idea of these measurements was limited to placing various stops between the camera and the object observed. The distance and depth of observation was chosen so that the object of interest was centred in the frame spatial recorded.

Sequentially, the drawings are schematic scenes of measuring and test the impact of fabric, artificial fog and fire curtains image quality. As reference there were presented the results obtained from other cameras (VIS, NIR, IR) observing the same scene at the same time.
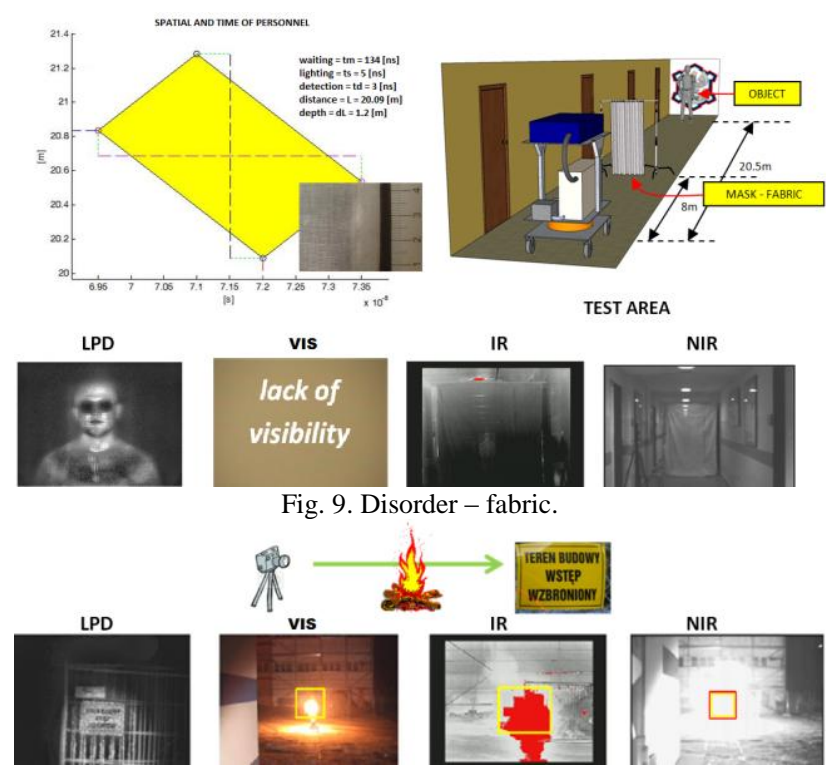

Fig. 10. Disorder - fire.
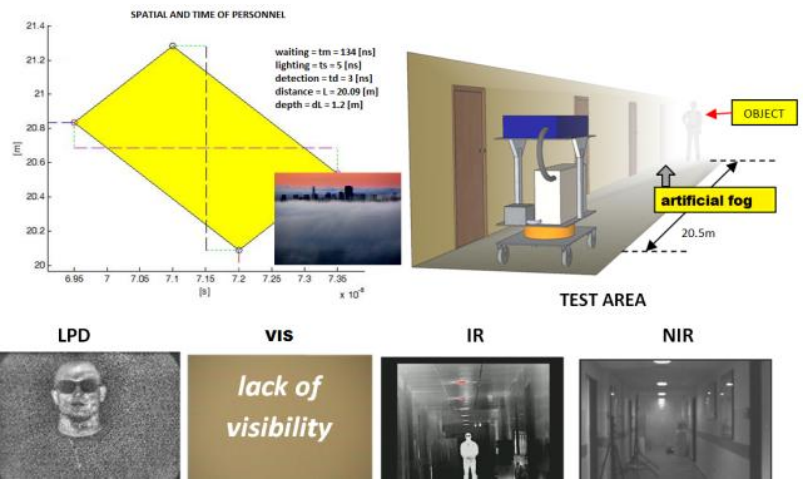

Fig. 11. Disorder - artificial fog.

Each of the presented examples shows how the Laser Photography Device handles the imaging facility in the face of an obscuring factor [7].

The method of spatio-temporal framing is the modern way of imaging, in which the users decide to observe a three-dimensional space that interests them, and thus are given the opportunity to minimize the impact of factors confounding image quality. The tests using Laser Devices Photography proved its operational effectiveness. Focusing the full power illumination onto a narrow spectral band and short-time (at the level of individual ns) and a narrow spectral observation, makes it possible to observe objects that are no longer perceived by other surveillance equipment.

This technique can have a very significant contribution to the development of systems for video monitoring, and reconnaissance imaging.

This work was funded by the Polish Ministry of Science and Higher Education (project OR00000312).

\section{References}

[1] L. Michalski, K. Eckersdorf ,J. Kucharski, Termometria-przyrządy $i$ metody (Wydawnictwo Politechniki Łódzkiej, Łódź 1998).

[2] K. Chrzanowski, K. Firmanty, J. Bareła, Krótkofalowe kamery podczerwieni (Pomiary Automatyka Robotyka 7-8/2005).

[3] M. Piszczek, K. Rutyna, M. Szustakowski, Europ. Phys. J.: Special Topics 154(1), 153 (2008).

[4] M. Piszczek, M. Kowalski, M. Szustakowski, K. Rutyna, K. Ludwikowski, Acta Phys. Pol. A 122(5), 862 (2012).

[5] M. Piszczek, K. Rutyna, Rejestracja obrazów metoda kadrowania czasoprzestrzennego (Pomiary Automatyka Kontrola 53, nr 9bis/2007).

[6] M. Piszczek, K. Rutyna, Roczniki geomatyki, Tom VI Zeszyt 7, 73 (2009).

[7] M. Piszczek, M. Zarzycki, Elektronika 10, 22 (2012). 